\title{
THE EFFECT OF MULTI-WALLED CARBON NANOTUBES ADDICTION ON THE PROPERTIES OF SHEAR THICKENING FLUIDS
}

\author{
Paulina NAKONIECZNA-DABROWSKA, Marcin LEONOWICZ \\ Warsaw University of Technology, Faculty of Material Science, Poland, EU, \\ paulina.nakonieczna.dokt@pw.edu.pl
}

https://doi.org/10.37904/nanocon.2021.4378

\begin{abstract}
Shear thickening fluid (STF) - often referred to as dilatant fluid - is a non-Newtonian suspension of a solid component in a liquid carrier, with an unique ability to dissipate the impact energy. The viscosity of STFs increases abruptly with a growing shear rate. Beyond the critical value of the shear rate, the fluid transforms from a liquid-like to a solid-like state. High-grade dilatant fluids, besides the appropriate rheological properties and protecting capability, have to present high structural stability. The unique properties of the STFs make them suitable for human body protection. The STFs provide lots of opportunities for creating composites with great energy absorption ability, for example, in smart armors or sports protectors.

The properties of shear thickening fluid, modified by the addition of multiwalled carbon nanotubes (MWCNT), were characterized. The addition of a small amount of carbon nanotubes to shear thickening fluid leads to an increase of maximal viscosity, from 2128 to $12213 \mathrm{~Pa}$. S. To show the differences between various compositions, the microstructures of fluids were observed by scanning electron microscopy (SEM). The pronounced influence of the MWCNT on the ability of impact force absorption was noticed. The protective structure containing 55 and 0.25 vol.\% of fumed silica and MWCNT, respectively, is able to absorb up to $74 \%$ of impact force.
\end{abstract}

Keywords: Carbon nanotubes, shear thickening fluids, scanning electron microscopy, nanomaterials

\section{INTRODUCTION}

A fluid is defined as a substance that flows, that is, deforms continuously over time [1]. The fluids include gases and liquids, as well as those solids that flow at certain, easily achievable conditions. Newtonian fluids comply with Newton's law - their viscosity is constant, independent of the shear rate, and the flow curve passes through the origin of the coordinate system. All fluids that do not comply with this law are called non-Newtonian - their viscosity depends on the speed and time of shearing [2]. Non-Newtonian fluids are divided into two groups: rheologically stable ones, which do not change rheological properties during shearing, and rheologically unstable ones whose rheological properties are a function of shear time [3], [4]. There are many rheological models, which is a more or less precise way, allow to describe the behavior of a given rheological system in conditions of low or high shear rates.

Shear thickening fluids (STF) display a dilation phenomenon which means that at a sufficiently high shear rate, their properties change from typical for liquids to characteristic for solids [5]. The viscosity of such liquids changes as a function of the shear rate. If the force acts at low speed, the liquid has a relatively low viscosity and does not put up much resistance. If the force acts rapidly, the viscosity of the liquid will also rise sharply, and the resistance will significantly increase [6-7]. The properties of such liquids can be controlled through their composition, which results in the change in the shear rate at which the viscosity (critical shear rate) and the maximum and initial viscosity increase [8]. 
STFs are promising for various applications, such as liquid body armor, sports protectors, such as smart knee pads, and others [9-12]. A variety of modifications have been introduced for the fabrication of composite STFs with different rheological properties. Ge et al. modified STFs with SiC nanowires [13]. Other studies have reported a minor addition of graphene and carbon nanotubes [14-16], in which the level of maximal viscosities obtained was below $1000 \mathrm{~Pa} \cdot \mathrm{s}$. Carbon additives seem to be the best fillers that have improved the maximal viscosity of STFs and also their stability [17]. Therefore, this topic should be investigated thoroughly by synthesizing new fluids whose properties may be unique and significantly better than the results already presented in this field of research.

\section{EXPERIMENTAL}

\subsection{Determination of static rheological properties of the developed dilatant fluids}

The ARES rotational rheometer was used to define the rheological properties of the fluids developed at room temperature in the parallel plate system using a $0.3 \mathrm{~mm}$ gap and $25 \mathrm{~mm}$ diameter plates. In the rotational rheometer, sample shearing occurs between two surfaces, where one is rotating, and the other is stationary. In static mode, the dependence of viscosity on the shear rate for all fluids developed was determined. The critical shear rate and the initial and maximum viscosity values were also established.

For the synthesis of shear thickening fluids, an amorphous silica KE-P50, with diameters ranging from 500 to $600 \mathrm{~nm}$, from Nippon Shokubai (Osaka, Japan), were mixed, in appropriate proportions, with polypropylene glycol PPG2000 from Acros Organics (Geel, Belgium), having a molar mass $2000 \mathrm{~g} / \mathrm{mol}$. The content of silica in the basic fluid was 50, 53 and 55 vol.\%. The composition of STFs was modified by the addition of the multiwalled carbon nanotubes (MWCNT, Nanocyl NC7000, Sambreville, Belgium), with the amounts of 0.05, 0.15 and 0.25 vol\%.

\subsection{Determination of the microstructure of shear thickening fluids through their observation using scanning electron microscope}

The test consisted of proper preparation of the fluid so that observation of the structure of shear thickening fluids using the SEM microscope is possible. The first step comprised a proper degassing, removing liquid phase to show the structure of the solid components. Degassing was performed by heating of the samples in vacuum. The resultant structure kept the solids intact so that visual observation of the interaction between the silica and the carbon fillers could be realized.

\subsection{Defining the ability to absorb impact force}

The ability to absorb the impact force was tested in accordance with the developed test procedure, which was prepared on the basis of the BS 7971-4:2002: Protective clothing and equipment for use in violent situations and in training. Part 4 - Limb protectors. Requirements and test methods. The fluids were closed in silicone molds. In the test, the hammer was dropped onto the sample with energy of $5 \mathrm{~J}$. This energy is obtained by means of the appropriately selected weight of the hammer and the height from which it is dropped. The sample is attached to the table with four two-kilo lead weights. Under the work table, there is a force sensor that records the change in the impact force overtime. Before the test, a reference measurement is carried out by dropping the hammer directly on the table and recording the maximum impact force. Subsequently, samples are placed on the table, and the hammer with the energy of $5 \mathrm{~J}$ is dropped.

\section{RESULTS AND DISCUSSION}

\subsection{Static rheological properties}

In Figure 1, the rheological properties of STFs with various additives are presented. 


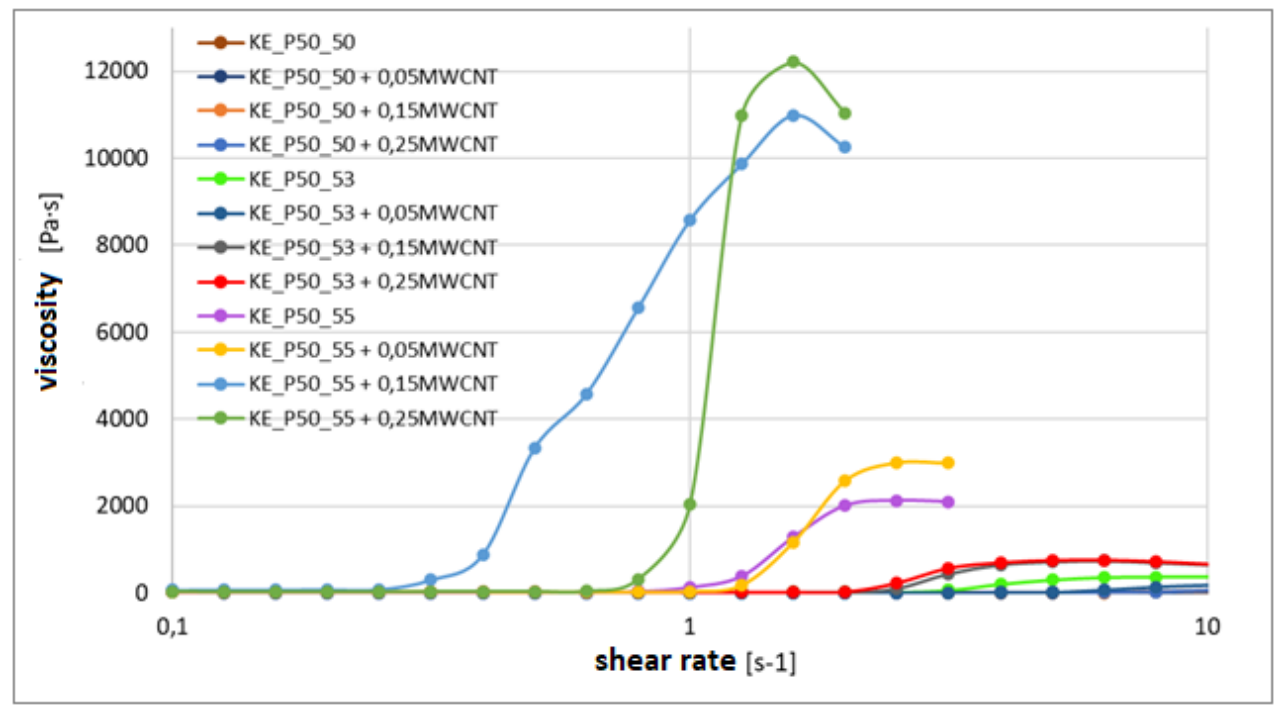

Figure 1 Viscosity vs. shear rate for the STFs with different contents of MWCNT

The highest viscosity and the critical shear rate, at which a drastic increase of the viscosity begins, depend on concentrations of both the silica and MWCNT. Increasing the volume fraction of MWCNT results in an increase in the value of the highest viscosity. The highest viscosity, $2213 \mathrm{~Pa} \cdot \mathrm{s}$ was recorded for the fluid containing 55 vol\% of silica and 0.25 vol.\% of MWCNT, with the critical shear rate below $2 \mathrm{~s}^{-1}$.

\subsection{Microstructure of shear thickening fluids}
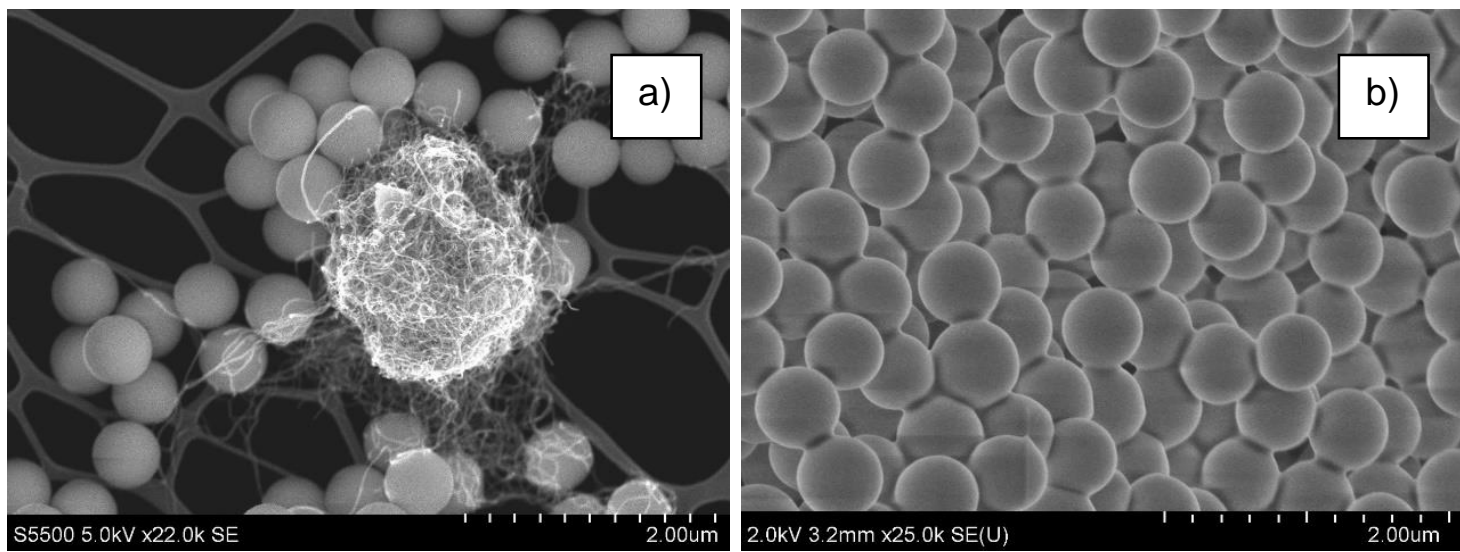

Figure 2 SEM images of a) the starting mixture of silica and agglomerates of MWCNT, b) the arrangement of solid components in the STF

The solid substrates of the STFs were subjected to SEM observations in Figure $\mathbf{2 a}$ ) and $\mathbf{2 b}$ ). Both the silica and the carbon nanotubes had a tendency to agglomeration. In Figure $\mathbf{2} \mathbf{b}$, the distribution of silica and carbon nanofillers in the STFs is shown. The agglomerates disappeared, and only silica particles were visible. Mixing silica with MWCNT in a carrier liquid leads to the breaking of the agglomerates of the nanotubes.

\subsection{Ability to absorb the impact force}

The shear thickening fluids were sealed in silicone moulds. During the tests, none of the samples were destroyed. The samples were deformed and then they returned to their initial shape. Figure 3 presents the values of the absorbed force for STFs sealed in silicone form after one, two, and three strikes at the same point with the addition of MWCNT. 


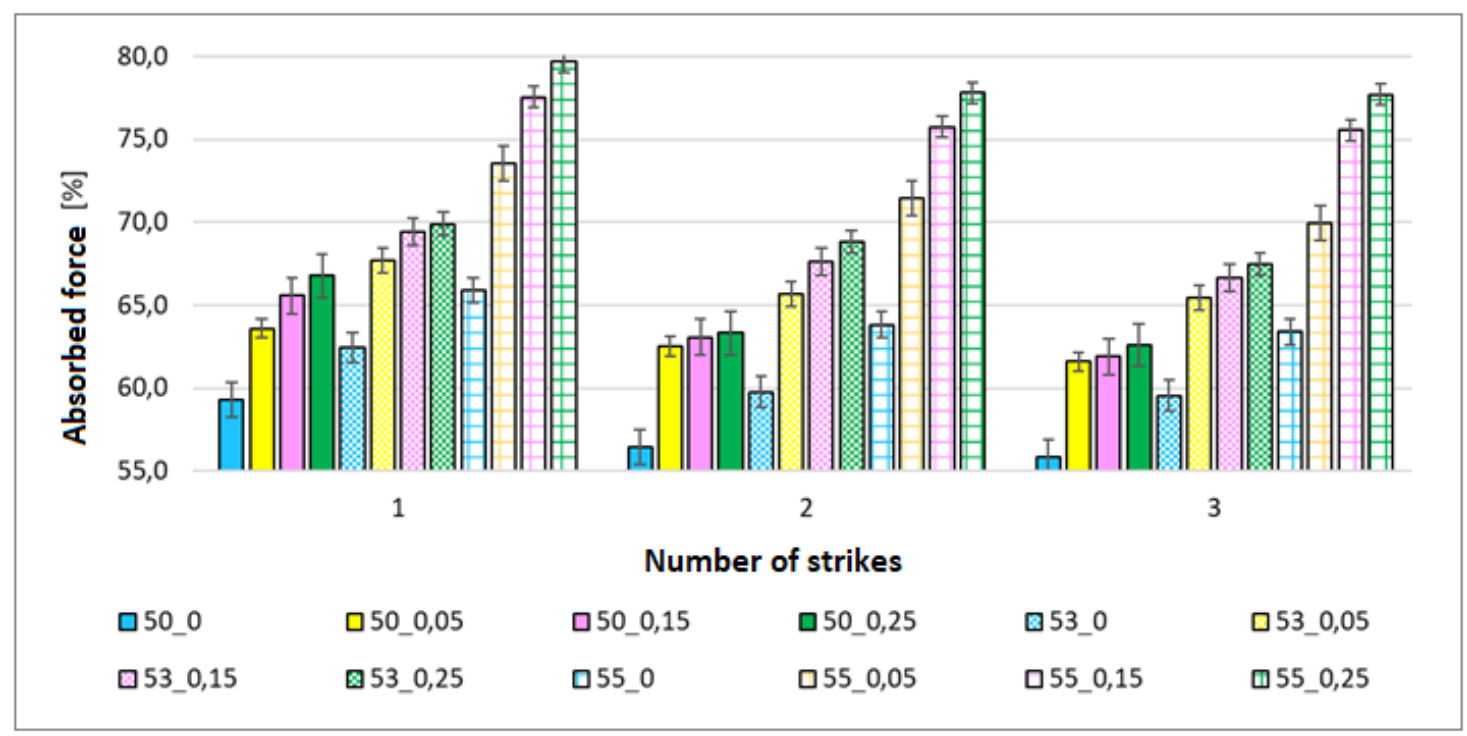

Figure 3 The percentage of absorbed force for STFs sealed in silicone forms after one, two, and three strikes at the same point, with various additions of MWCNT

The higher addition of MWCNT provides an increase of the absorbed force. The samples containing 53 and 55 vol\% silica and 0.25 vol\% MWCNT show the highest absorbing properties (above $70 \%$ for the first strike). One can clearly see that the STFs modified by MWCNT have a greater ability to absorb impact force than the ones based on fumed silica only.

\section{CONCLUSION}

Shear thickening fluids based on amorphous silica and multi-walled carbon nanotubes were produced. The results show that the addition of the MWCNT has a significant influence on the maximum viscosity, critical share rate and impact force absorbing efficiency. The STFs containing MWCNT have great potential for application in smart protective structures, such as sports protectors, helmets, liquid body armor, and many other applications.

\section{ACKNOWLEDGEMENTS}

\section{The research was financed from the Subsidy Research Funds of the Warsaw University of Technology.}

The publication was financed from the "Excellence initiative - research university" (IDUB), program "Mobilność Doktorantów Studiów Doktoranckich"

\section{REFERENCES}

[1] YOUNG, D.F.; MUNSON, B.R.; OKIISHI, T.H.; HUEBSCH, W.W. A Brief Introduction to Fluid Mechanics, $4^{\text {th }}$ ed.; NJ, USA, Wiley: Hoboken, 2007.

[2] MEWIS J., WAGNER N. J. Colloidal suspension rheology. Cambridge University Press, 2012.

[3] JANMEY P. A., WILLIAMS N., Quick guide: Rheology. Current Biology. 2010, pp. 639-641.

[4] BINGHAM E. C. Some Fundamental Definitions of Rheology. Journal of Rheology. 2005, vol. 1, pp. 5.

[5] FREUNDLICH H., RÖDER H. L. Dilatancy and its relation to thixotropy. Trans. Faraday Soc. 1938, vol. 34, pp. 308316. 
[6] BOSCO A., CALADO V., MAIA J. Rheological parameters of shear-thickening fluids using an experimental design. Mater. Res. 2019, vol. 22, 5, pp. 1-9.

[7] BARNES, H.A. Shear-Thickening ("Dilatancy") in Suspensions of Nonaggregating Solid Particles Dispersed in Newtonian Liquids. J. Rheol. 1989, vol. 33, pp. 329-366.

[8] WAGNER N.J., BRADY J. F., Shear thickening in colloidal dispersions. Phys. Today. 2009, vol. 62, p. 27.

[9] LEE, Y.S., WETZEL, E.D., WAGNER, N.J. The ballistic impact characteristics of Kevlar® woven fabrics impregnated with a colloidal shear thickening fluid. J. Mater. Sci. 2003, vol. 38, pp. 2825-2833.

[10] QIN, J.; ZHANG, G.; ZHOU, L.; LI, J.; SHI, X. Dynamic/quasi-static stab-resistance and mechanical properties of soft body armour composites constructed from Kevlar fabrics and shear thickening fluids. RSC Adv. 2017, vol. 7, pp. 39803-39813.

[11] TIAN, T.; NAKANO, M.; LI, W. Applications of shear thickening fluids: A review. Int. J. Hydromechatron. 2018, vol. 1, pp. 238-257.

[12] KUCSHAN, M.C.; GÜRGEN, S.; ÜNALIR, T.; ÇEVIK, S. A novel approach for armor applications of shear thickening fluids in aviation and defense industry. Int. Conf. Sci. 2014, vol. 22, pp. 4.

[13] GE, J.; TAN, Z.; LI, W.; ZHANG, H. The rheological properties of shear thickening fluid reinforced with SiC nanowires. Results Phys. 2017, vol. 7, pp. 3369-3372.

[14] EGRES R. G., WAGNER N. J., The rheology and microstructure of acicular precipitated calcium carbonate colloidal suspension through the shear thickening transition. Journal of Rheology. 2005, vol. 49, pp. 719.

[15] YU K., CAO H., QIAN K., SHA X., CHEN Y. Shear-thickening behavior of modified silica nanoparticles in polyethylene glycol. J. Nanopart. Res. 2021, vol. 14, p. 747.

[16] MAJUMDAR S., KRISHNASWAMY R., SOOD A. K., Discontinuous shear thickening in confined dilute carbon nanotube suspensions. Proc. Natl. Acad. Sci. 2011, vol. 108, pp. 8996-9001.

[17] WEI M., Y. SUN Lv, L., SUN H. Rheological properties of multi-walled carbon nanotubes / silica shear thickening fluid suspensions Rheological properties of multi-walled carbon nanotubes / silica shear thickening fluid suspensions. Colloid Polym. Sci. 2020, vol. 298, pp. 243-250. 